\title{
BMJ Open Communication skills attitude scale: a translation and validation study in asample of registered nurses in Poland
}

\author{
Mariusz Panczyk, ${ }^{\circledR}$ Lucyna Iwanow, Aleksander Zarzeka, Mariusz Jaworski, \\ Joanna Gotlib
}

To cite: Panczyk M, Iwanow L, Zarzeka A, et al. Communication skills attitude scale: a translation and validation study in asample of registered nurses in Poland. BMJ Open 2019;9:e028691. doi:10.1136/ bmjopen-2018-028691

- Pre-publication history and additional material is published online only. To view, please visit the journal online (http://dx.doi. org/10.1136/bmjopen-2018028691).

Received 19 December 2018

Revised 11 March 2019

Accepted 11 April 2019

Check for updates

(C) Author(s) (or their employer(s)) 2019. Re-use permitted under CC BY-NC. No commercial re-use. See rights and permissions. Published by BMJ.

Department of Education and Research in Health Sciences , Faculty of Health Sciences, Medical University of Warsaw, Warsaw, Poland

Correspondence to

Prof. Mariusz Panczyk;

mariusz.panczyk@wum.edu.pl

\section{ABSTRACT}

Objectives To translate and validate the Communication Skills Attitude Scale in the Polish language (CSAS-P) and its adaptation for use among registered nurses.

Design A cross-sectional descriptive design was used in order to translate and validate the CSAS-P. The following psychometric properties of CSAS-P were evaluated: content validity (content validity index), theoretical relevance (exploratory and confirmative factor analysis), one-dimensionality of subscales (principal component analysis), internal consistency (Cronbach's $\alpha$ ), test-retest reliability and discriminant validity.

Setting Participants were identified and recruited from the Centre for Postgraduate Education for Nurses and Midwives in Warsaw, Poland.

Participants The validation group comprised 2014 registered nurses who were undertaking a spring specialisation exam in 2017.

Results The overall content validity index was $>0.80$, which was interpreted as indicating validity. The factor structure of CSAS-P differed from the original version, and removing three items from the scale better fit the data. The positive attitude subscale ( 11 items) and negative attitude subscale (12 items) were characterised by one-dimensionality and high internal consistency (Cronbach's $\alpha=0.901$ and 0.802 , respectively). Test-retest analysis confirmed the stability of the measurement for both subscales and particular items. Nurses with prior participation in communication courses scored significantly higher than those without such education $(p<0.05)$, confirming the discriminant validity of CSAS-P. Conclusions The psychometric properties of CSAS-P were comparable to the English language original. Further validation of CSAS-P in other groups of healthcare professionals may increase its applicability. CSAS-P can be used to evaluate attitudes towards learning communication skills among registered nurses.

\section{INTRODUCTION}

Social skills, including communication, are necessary in the work of healthcare professionals, in addition to the hard-professional competences. These skills are of particular importance in human-focused professions such as nursing. ${ }^{1}$ Ineffective communication between the patient and members of the

\section{Strengths and limitations of this study}

The study adapted and validate the Communication Skills Attitude Scale (CSAS) in a registered nurses population in Poland through a rigorous methodological approach.

- The aforementioned scale was validated through exploratory and confirmative factor analysis, internal consistency and test-retest reliability in order to describe its psychometric properties.

- The study provided information on the validity of the CSAS scale on Polish nurses sample.

- Further validation of Polish version of CSAS in other groups of healthcare professionals may increase its applicability.

therapeutic team can negatively affect treatment outcomes. ${ }^{2}$ Alternatively, good communication can enable better diagnosis, increase patient compliance with treatment recommendations, ${ }^{2}$ reduce the number of medical errors committed by medical personnel ${ }^{3}$ and have a positive effect on the patient's mood and satisfaction. ${ }^{4}$ Therefore, improving the quality of communication between participants of the healthcare system is a global priority. $^{5}$

Because of the important role of nursing in the modern model of patient care, nurses must have high communication competencies, ${ }^{1}$ which takes into account shared decision-making in nursing practice. Shared decision-making is defined as a process taking place during a healthcare encounter with implications for the continuation of shared decisions over time offering patients an opportunity to return to the nurse for reconsiderations of past shared decisions. This approach prevent common communication errors. ${ }^{6}$ The most common communication errors made by nurses are in tailoring information to what the patients want to know, verifying their understanding and eliciting their perception of their main problem. 
Deficiencies in communication also lead to conflicts between members of the therapeutic team and increase aggressive behaviour of the staff towards patients; a tense atmosphere in the ward can contribute to increased aggression in patients inter alia towards nurses. Moreover, exposure to conflict and aggression promotes the development of avoidance, which leads to a deterioration of relationships between collaborators and patients in the long term, and is considered as one of the reasons for professional burnout. ${ }^{8}$

The increased interest in shaping communication competences in students and healthcare professionals is reflected in study programmes, international consensus statements and professional practice standards. ${ }^{5}$ It should be emphasised that the attitude is expressed in three important dimensions-cognitive (knowledge), emotional (emotions) and behavioural. Therefore, shaping an attitude is a comprehensive process. ${ }^{9}$ Focusing only on knowledge transfer and teaching of communication skills does not guarantee that a given person will recognise the usefulness of these skills in clinical practice. Therefore, it is important to shape positive attitudes among nurses, by stressing the importance of good communication for improving patient care. ${ }^{10}$

Data indicate that a well-planned process of learning communication skills can lead to positive attitudes of participants, but not in all cases. ${ }^{11}$ For example, there are some people who have a positive attitudes, but do not see the need to learn these skills. For this reason, in nursing education, it is necessary to learn much more about the mediating factors between a positive attitude and the need to shape communication skills. In this case, personal convictions could be important. ${ }^{12}$ Course planners should consider the individual attitudes of participants towards the studied subject. ${ }^{11}$ Thus, assessing the attitudes of nursing students and practitioners towards learning communication skills should form part of the design of education programmes. ${ }^{13}$ For this purpose, existing standardised measurement tools can be used, including the commonly used Communication Skills Attitude Scale (CSAS) ${ }^{14}$ It will be possible to take appropriate actions to enhance this positive attitude, and the factors determining the need to learn these skills.

Due to its good psychometric parameters and availability in many different language versions, CSAS is considered an international standard for assessing attitudes in this area. In addition to the original English language version of CSAS, validation has been done for Norwegian, ${ }^{15}$ Portuguese, ${ }^{16}{ }^{17}$ Catalan, ${ }^{13}$ German ${ }^{18}$ and Finnish ${ }^{11}$ versions. CSAS was originally designed and used predominantly for evaluating medical students; the only CSAS version that has been developed and validated for assessment of attitudes in nursing students was one developed in the Catalan language. ${ }^{13}$ As there is currently no standardised tool in Poland that could be used to evaluate the attitudes of nursing students and practitioners towards learning communicative competence, a Polish language version of CSAS was developed.
The purpose of the study is twofold one. First, to translate and validate the multidimensional CSAS in Polish and second to validate the scale in a group of registered nurses. This is a major contribution to the relevant literature as the original study as well as the subsequent validations studies did not test the CSAS in population of registered nurses.

\section{METHODS}

\section{Design, sample population}

This cross-sectional survey study was conducted from March 2017 to May 2017. Potential participants in the study were identified and recruited from the Centre for Postgraduate Education for Nurses and Midwives in Warsaw, Poland. All registered nurses, who participated in a spring specialisation training programme in 2017, were invited to take part in the study. Participation in the study was voluntary and anonymous. Results were collected using an auditorium method, whereby respondents filled in the questionnaires individually in one room. By virtue of large number of participants of the study, the random survey was conducted in 20 turns. Every time the place and procedure of the study was identical.

A group of registered nurses, recruited from among 200 M.A. studies, studying at the Medical University of Warsaw, Poland, participated in the component of the study where absolute stability (test-retest analysis) was evaluated. Retesting was performed 4 weeks after the original test. A full set of data was collected from 110 students.

\section{Patient and public involvement}

Neither patients nor the general public were involved in this research project.

\section{Instruments}

CSAS was designed and validated by Rees $e t a l^{14}$ to assess the attitudes of medical students towards acquisition of communication competencies. Validation of the original English version of CSAS was performed by analysing the psychometric characteristics of the scale in a total of 490 students from two UK universities.

Factorial structure analysis of the CSAS English version revealed that 26 items of the scale constituted two components: the positive and negative attitudes subscales (PAS and NAS). ${ }^{14}$ Each of the 13 items constituting the two subscales was evaluated using 5-point Likert scales (from 1-strongly disagree to 5-strongly agree). Before analysing the data, the scores for the 13 negative items were reversed to obtain the same direction of scores for both negative and positive items. The higher the overall score reached by a respondent, the stronger their positive attitude towards learning communication skills.

The English language version of CSAS is characterised by good internal consistency, test-retest reliability and discriminant validity. ${ }^{14}$ Furthermore, published results of studies using different language versions of CSAS in different groups of students and practitioners allows us 
to assume it is an appropriate tool for evaluating attitudes towards communication skills education. ${ }^{11} 131516$ 18-25

\section{Procedure}

Consent was obtained from the author of the original version of CSAS for its use in research conducted by Medical University of Warsaw. Norwegian and Catalan CSAS versions were also used when preparing CSAS-P on consent of the authors. ${ }^{13} 15$ To carry out the linguisticcultural adaptations and the validation process, guidance provided by the WHO recommendations for "process of translation and adaptation of instruments ${ }^{26}$ and Sousa and Rojjanasrirat ${ }^{27}$ were used when preparing CSAS-P. CSAS (in the form proposed by Rees et $a l^{14}$ ) was translated into Polish by three independent translators: one version of the translation from Norwegian, and one from Catalan, was also prepared. To adapt the tool for application in nursing students and practitioners, terms 'doctor', 'medical' and 'medicine' were changed to 'nurse' and 'nursing'. Reviewing and comparing all translations revealed high similarity. The concerted Polish version was subject to back translation, which was submitted to the authors of the original version of CSAS for review. The final version of CSAS-P was then validated after taking all reviewers' comments into account.

The questionnaire was supplemented with two additional questions: the first concerned self-assessment of the level of communication skills (response categories: low, medium and high), and the second referred to declared participation in any education programme on communication competence in the past. The form was completed with another personal questionnaire regarding sex, age, years of work in profession, particular profession, place of residence, education and work place.

\section{Data analysis}

To evaluate the psychometric properties of CSAS-P, the factorial structure, one-dimensionality, reliability (internal consistency and test-retest reliability) and discriminant validity was assessed. The scale was reversed prior to the analyses of negatively phrased items.

Content validity index (CVI) was performed to quantified content validity in the validation. The experts were asked to score the validity of the clinical scenario and items using a 4-point Likert scale ranging from 1 to 4 (1=notrelevant, 2=somewhat relevant, 3=quite relevant, $4=$ highly relevant). The team of experts included representatives of the Polish Nursing Association, Student's Self-Government, Director for Nursing of the Clinical Hospital, a psychologists and an experienced nursing educators with extensive seniority. Then, for each item, the CVI is computed as the number of experts giving a rating of either 3 or 4 (thus dichotomising the ordinal scale into relevant and not relevant), divided by the total number of experts. A CVI of $>0.80$ was interpreted as indicating validity. ${ }^{28}$

Exploratory factor analysis (EFA) with direct oblimin rotation was used to evaluate construct validity. The number of factors was determined on the basis of two criteria: Kaiser $^{29}$ and Cattell. ${ }^{30}$ Items to be included in their respective factors were made on a priori grounds, that is, based on items that loaded at $>0.40$ on one factor and at least 0.10 lower on another factor. ${ }^{15}$

Confirmatory factor analysis (CFA) was used to assess the fit of the results to the imposed two-factorial structure resulting from theoretical assumptions (as in the English language version ${ }^{14}$ ), or with the one resulting from EFA. CFA results for different factorial models were compared based on the following indices: goodness-of-fit index (GFI Jöreskog), adjusted goodness-of-fit index (AGFI), root mean square error of approximation (RMSEA Steigera-Linda) and Akaike Information Criterion (AIC). The GFI and AGFI values should be at least 0.95 while RMSEA should be 0.05 or less. The AIC value allows for the comparison of two different models, where the preferred model has the lower AIC. ${ }^{31}$

One-dimensionality for each CSAS-P subscale was determined by principal component analysis. The subscale that meets the Kaiser criterion (eigenvalue exceeds the value 1 only once) was considered as one-dimensional, and it was assumed that the degree of reproducibility of the indicator variables by the first principal component should exceed $40 \% .^{29}$

Internal consistency of the CSAS-P subscales was assessed by Cronbach's formula: a threshold for Cronbach's $\alpha>0.70$ was considered satisfactory according to Nunnally and Bernstein criterion. ${ }^{32}$

The estimation of test-retest reliability was planned for a group of 110 second-year (bachelor degree) nursing students. The repeat CSAS-P test was done 2 weeks after the first, with a complete dataset obtained for 91 students. Absolute stability was measured by calculating the weighted kappa coefficient and interclass correlation coefficient (ICC), which determine the level of consistency between the answers given at the first and second measurements. ${ }^{33}$

External validity was estimated by assessing the ability of the scale to show differences between groups (discriminative validity). In the first evaluation, group 1 included respondents who declared they previously participated in communication skills education, and group 2 included those without such a declaration. It was assumed that the overall results, particularly those for the PAS-P subscale for the first group, should be significantly higher than the second. In the second evaluation of discriminative validity, differences in the scores obtained by respondents with different declared communication skills were assessed. It was assumed that people with higher declared skill level would obtain significantly better overall results and scores in each CSAS-P subscale. Two-way analysis of variance (two-way ANOVA) with post hoc analysis with Tukey's honest significant difference (HSD) test was used for the comparison. The size of the estimated effect was expressed by eta-squared $\left(\eta^{2}\right)$. The following criteria for the effect size were used: $0.01-$ small, 0.06-medium, 0.14 - large. ${ }^{34}$ 


\begin{tabular}{|c|c|}
\hline & N (\%) \\
\hline \multicolumn{2}{|l|}{ Gender } \\
\hline $\begin{array}{l}\text { Female } \\
\text { Male } \\
\text { No data }\end{array}$ & $\begin{array}{r}1751(87.0) \\
69(3.4) \\
194(9.6)\end{array}$ \\
\hline \multicolumn{2}{|l|}{ Residence } \\
\hline $\begin{array}{l}\text { Countryside } \\
\text { City up to } 50000 \\
\text { City } 51-200000 \\
\text { City } 201-500000 \\
\text { City }>500000 \\
\text { No data }\end{array}$ & $\begin{array}{l}465(23.1) \\
375(18.6) \\
423(21.0) \\
245(12.2) \\
299(14.8) \\
207(10.3)\end{array}$ \\
\hline \multicolumn{2}{|l|}{ Education } \\
\hline $\begin{array}{l}\text { Secondary medical } \\
\text { Bachelor degree } \\
\text { Master degree } \\
\text { Doctorate } \\
\text { No data }\end{array}$ & $\begin{array}{r}383(19.0) \\
562(27.9) \\
860(42.7) \\
12(0.6) \\
197(9.8)\end{array}$ \\
\hline \multicolumn{2}{|l|}{ Workplace* } \\
\hline $\begin{array}{l}\text { City hospital } \\
\text { Clinical hospital } \\
\text { General outpatient clinic } \\
\text { Specialist outpatient clinic } \\
\text { Home care } \\
\text { Other } \\
\text { No data }\end{array}$ & $\begin{array}{l}927(46.0) \\
633(31.4) \\
137(6.8) \\
113(5.6) \\
102(5.1) \\
491(24.4) \\
215(10.7)\end{array}$ \\
\hline
\end{tabular}

${ }^{*}$ The respondents could indicate more than one place of work.

All statistical calculations were performed using the statistical package IBM SPSS Statistics, V.23. A p value $<0.05$ was considered to be statistically significant.

\section{RESULTS}

\section{Participant characteristics}

Survey data were collected for 2014 registered nurses from a total of 4119 participants who were taking the exam during this period ( $48.9 \%$ return rate). Table 1 reports the demographic characteristics of the participants who completed this study. The average age of respondents was 42.5 years $(\mathrm{SD}=7.72)$, and average number of years of work in the profession was $18.9(\mathrm{SD}=8.90)$. The sample was representative in terms of the mean age $(\mathrm{t}=0.407$, $\mathrm{p}=0.684)$ and the selected specialisation $\left(\chi^{2}=10.112\right.$, $\mathrm{p}=0.606$ ) with regard to all participants in the examination session.

\section{Content validity}

The CVI evaluation form was distributed to seven experts who were asked to rate content validity on the 26-item questionnaires regarding the agreement or disagreement with statements. The overall CVI was 0.95 and each individual item CVI was above the 0.86 level of agreement in the CSAS-P.

\section{Construct validity}

The value of the correlation matrix was close to zero, and the correlation matrix was not an identity matrix (Bartlett's test of sphericity, $\mathrm{p}=0.000$ ). The Kaiser-Mayer-Olkin index (sampling accuracy) was 0.932 , which fulfils the assumptions for this parameter $(>0.5)$.

In the first EFA attempt, the 26 items distributed according to the Kaiser criterion into four factors, explaining in total $48 \%$ of the total variance. Such a set of factors was not, however, compatible with the concept of division of CSAS into two subscales. In contrast, the course of the scree plot indicated a two-factor solution (the total variance explained was $40 \%$ ). Therefore, a two-factor solution was adopted in accordance with the assumptions resulting from the validation of the original CSAS version. The solution largely confirmed the proposed CSAS structure (table 2).

In the PAS subscale, two items-12 ('learning communication skills is fun') and 22 ('my ability to pass exams will get me through medical school rather than my ability to communicate')—did not meet the assumed value of the load; similarly for item 1 in the NAS subscale ("in order to be a good nurse I must have good communication skills"). Therefore, in further analysis, two models of CSAS: one based on the original version (all 26 items) and one where the scale was reduced to 23 items (ie, deleted items 1, 12 and 22) were evaluated (see details in online supplementary file 1 ).

The degree of fit of both models to the collected data was then compared using CFA. The results for the original subscales were less satisfactory (table 3), confirming the two-factor model of EFA. Consequently, the CSAS-P subscales described in the EFA were used for further calculations. All additional results of EFA and CFA for each alternative model of CSAS are included in the online supplementary file 2 .

\section{Unidimensionality of subscales}

The one-dimensionality of each subscale was analysed using principal component analysis. For both subscales, only one of the two conditions of unidimensionality was fulfilled: for the PAS-P subscale, two eigenvalues were noted $>1.00$; while for NAS-P subscale, the total variance explained by the first principal component was $<40 \%$.

\section{Internal consistency}

No items had a SD of zero. The lowest score for the entire Polish language version of CSAS was observed in $0.05 \%$ of cases while the highest one was obtained by $0.40 \%$ of all. The above-mentioned results demonstrated a lack of floor or ceiling effects. Both subscales showed good internal consistency (ie, Cronbach's $\alpha$ of $>0.700-0.901$ for PAS-P and $>0.802$ for NAS-P). The correlation value was lower than the assumed threshold only for item 3 (table 4).

\section{Test-retest reliability}

Evaluation of test-retest reliability showed good stability of CSAS-P and its subscales. Assumptions regarding the 
Table 2 Rotated pattern matrix with loadings for each item
on each of the two factors

\begin{tabular}{|c|c|c|}
\hline \multirow[b]{2}{*}{ Item } & \multicolumn{2}{|c|}{ Factor loading } \\
\hline & I (PAS) & II (NAS) \\
\hline CSAS_4 & 0.672 & -0.012 \\
\hline CSAS_5 & 0.719 & -0.058 \\
\hline CSAS_7 & 0.639 & 0.087 \\
\hline CSAS_9 & 0.749 & 0.086 \\
\hline CSAS_10 & 0.750 & 0.027 \\
\hline CSAS_12 & 0.118 & -0.360 \\
\hline CSAS_14 & 0.750 & -0.029 \\
\hline CSAS_16 & 0.760 & -0.055 \\
\hline CSAS_18 & 0.631 & -0.085 \\
\hline CSAS_21 & 0.727 & 0.097 \\
\hline CSAS_22 & 0.139 & -0.513 \\
\hline CSAS_23 & 0.689 & -0.064 \\
\hline CSAS_25 & 0.703 & 0.054 \\
\hline CSAS_1* & -0.535 & -0.066 \\
\hline CSAS_2 & 0.204 & 0.532 \\
\hline CSAS_3 ${ }^{*}$ & -0.078 & 0.260 \\
\hline CSAS_6 & 0.209 & 0.520 \\
\hline CSAS_8* & 0.222 & 0.599 \\
\hline CSAS_11* & 0.04 & 0.637 \\
\hline CSAS_13* & 0.102 & 0.563 \\
\hline CSAS_15 & -0.043 & 0.484 \\
\hline CSAS_17 $7^{*}$ & -0.169 & 0.578 \\
\hline CSAS_19* & 0.256 & 0.569 \\
\hline CSAS_20* & -0.023 & 0.414 \\
\hline CSAS_24 & 0.206 & 0.631 \\
\hline CSAS_26 ${ }^{*}$ & 0.165 & 0.635 \\
\hline
\end{tabular}

${ }^{*}$ Negatively phrased items were reverse-scored before analysis. CSAS, Communication Skills Attitude Scale; NAS, negative attitude subscale; PAS, positive attitude subscale.

stability of the remeasurement results were met and the ranges of weighted kappas and ICCs were satisfactory (table 5). The test-retest analysis for the PAS-P measured by an ICC was 0.895 (95\% CI 0.888 to 0.902 ) ( $\mathrm{F}=9.929$,
Table 4 Internal consistency and item analysis for CSAS-P

\begin{tabular}{|c|c|c|c|}
\hline Items & Mean & SD & $\begin{array}{l}\text { Correlation } \\
\text { item-total }\end{array}$ \\
\hline \multicolumn{4}{|l|}{ PAS-P } \\
\hline CSAS_4 & 4.2 & 1.08 & 0.592 \\
\hline CSAS_5 & 4.1 & 1.18 & 0.619 \\
\hline CSAS_7 & 3.9 & 1.10 & 0.575 \\
\hline CSAS_9 & 4.2 & 1.03 & 0.696 \\
\hline CSAS_10 & 4.1 & 1.04 & 0.692 \\
\hline CSAS_14 & 4.1 & 1.10 & 0.667 \\
\hline CSAS_16 & 4.0 & 1.12 & 0.676 \\
\hline CSAS_18 & 3.7 & 1.15 & 0.546 \\
\hline CSAS_21 & 4.2 & 1.02 & 0.670 \\
\hline CSAS_23 & 3.9 & 1.10 & 0.602 \\
\hline CSAS_25 & 4.2 & 1.04 & 0.641 \\
\hline \multicolumn{4}{|l|}{ NAS-P } \\
\hline CSAS_2* & 4.0 & 1.35 & 0.500 \\
\hline CSAS_3 ${ }^{*}$ & 2.9 & 1.32 & $0.176 \dagger$ \\
\hline CSAS_6 ${ }^{*}$ & 3.5 & 1.38 & 0.490 \\
\hline CSAS_8* & 3.6 & 1.32 & 0.571 \\
\hline CSAS_11 ${ }^{*}$ & 3.4 & 1.32 & 0.517 \\
\hline CSAS_13* & 3.5 & 1.17 & 0.437 \\
\hline CSAS_15 ${ }^{*}$ & 3.0 & 1.23 & 0.339 \\
\hline CSAS_17 $7^{*}$ & 3.2 & 1.29 & 0.376 \\
\hline CSAS_19* & 3.8 & 1.37 & 0.536 \\
\hline CSAS_20* & 3.5 & 1.32 & 0.299 \\
\hline CSAS_24* & 3.6 & 1.27 & 0.580 \\
\hline CSAS_26* & 3.7 & 1.43 & 0.555 \\
\hline
\end{tabular}

${ }^{\star}$ Negatively phrased items were reverse-scored before analysis. $\dagger<0.200$.

CSAS, Communication Skills Attitude Scale; NAS, negative attitude subscale; PAS, positive attitude subscale.

$\mathrm{p}=0.000)$. Test-retest analysis for the NAS-P measured by an ICC was 0.789 (95\% CI 0.771 to 0.805$)(\mathrm{F}=5.055$, $\mathrm{p}=0.000)$.

\section{Discriminant validity}

Both in the two subscales and overall total score, the average score of respondents who declared participation

Table 3 Goodness of fit of models to collected data

\begin{tabular}{llll}
\hline Fit indices & Good model fit & $\begin{array}{l}\text { Original model } \\
\text { CSAS }^{*}\end{array}$ & $\begin{array}{l}\text { Modified model } \\
\text { CSAS-P† }\end{array}$ \\
\hline Goodness-of-fit index (Jöreskog) & Close to 1.00 & 0.889 & 0.922 \\
Adjusted goodness-of-fit index & Close to 1.00 & 0.869 & 0.906 \\
Root mean square error of approximation (Steigera-Linda) & $\leq 0.05$ & 0.068 & 0.059 \\
Akaike information criterion (AIC) & Lower AIC & 1.561 & 0.947 \\
\hline
\end{tabular}

* Model with 26 items based on findings of Rees et al.

†Model with 23 items obtained after deleting items 1, 12 and 22.

CSAS, Communication Skills Attitude Scale. 
Table 5 Test-retest reliability of CSAS-P

\begin{tabular}{|c|c|c|c|}
\hline Item & $\begin{array}{l}\text { Measure of agreement } \\
\text { Weighted kappa }\end{array}$ & Levels of agreement ${ }^{\star}$ & $\mathrm{ICC} \dagger$ \\
\hline CSAS_2 & 0.551 & Moderate & 0.897 \\
\hline CSAS_3 & 0.769 & Substantial & 0.942 \\
\hline CSAS_4 & 0.962 & Excellent & 0.989 \\
\hline CSAS_5 & 1.000 & Excellent & 1.000 \\
\hline CSAS_6 & 0.551 & Moderate & 0.918 \\
\hline CSAS_7 & 0.871 & Excellent & 0.961 \\
\hline CSAS_8 & 0.774 & Substantial & 0.854 \\
\hline CSAS_9 & 0.763 & Substantial & 0.921 \\
\hline CSAS_10 & 0.909 & Excellent & 0.966 \\
\hline CSAS_11 & 0.538 & Moderate & 0.892 \\
\hline CSAS_13 & 0.863 & Excellent & 0.963 \\
\hline CSAS_14 & 0.851 & Excellent & 0.954 \\
\hline CSAS_15 & 0.747 & Substantial & 0.934 \\
\hline CSAS_16 & 0.851 & Excellent & 0.955 \\
\hline CSAS_17 & 0.487 & Moderate & 0.866 \\
\hline CSAS_18 & 0.719 & Substantial & 0.911 \\
\hline CSAS_19 & 0.848 & Excellent & 0.971 \\
\hline CSAS_20 & 0.626 & Substantial & 0.922 \\
\hline CSAS_21 & 0.806 & Excellent & 0.936 \\
\hline CSAS_23 & 0.570 & Moderate & 0.863 \\
\hline CSAS_24 & 0.722 & Substantial & 0.930 \\
\hline CSAS_25 & 0.854 & Excellent & 0.953 \\
\hline CSAS_26 & 0.742 & Substantial & 0.949 \\
\hline
\end{tabular}

*Weighted kappa: 0.41-0.60 moderate; $0.60-0.80$ substantial; $>0.80$ excellent.

†ICCs: $>0.75$ good reliability, $<0.75$ moderate-to-poor reliability.

CSAS, Communication Skills Attitude Scale; ICC, intraclass correlation coefficient.

in courses improving communication skills in the past was significantly higher than those who did not make such a declaration. Participation in communication courses had an average impact on CSAS-P measurement results. Analysis of differences depending on the declared communication skills level showed significant differences in the CSAS-P and PAS-P subscales. In both cases, the differences were related to the subjects with high selfrating compared with those with low and average levels of declared skills (results of Tukey's HSD test not shown). The results of the two-way ANOVA did not show any interaction between the two intergroup factors: training and self-assessment of communication skills level. The results of discriminant validity by intergroup differences method are presented in table 6 .

\section{DISCUSSION}

Overall, the validation results indicate a high degree of similarity of CSAS-P with the original scale developed by Rees $e t a l^{14}$ in terms of selected psychometric features. However, some differences were observed. In particular, when evaluating the factorial structure, the initial solution indicated a four-element structure for CSAS-P, while Rees $e t a l^{14}$ achieved a six-element solution. The results of others also indicate several components of CSAS: Laurence $e t a l^{24}$ ( 4 factors); Anvik et $a l^{15}$ ( 5 factors); Harlak et $a l,{ }^{21}$ Ahn $e t a l,{ }^{19}$ Molinuevo and Torrubia ${ }^{13}$ (6 factors) and Busch et $a l^{18}$ (7 factors). Although the EFA results indicated a structure of more than two elements, the CSAS developers decided to impose a two-factor solution in line with the theoretical assumptions. A similar solution was adopted in this study when validating CSAS-P, as done by other authors. ${ }^{13151821}$ A CSAS-P structure other than the assumed one denotes the reduced theoretical accuracy of the scale. A validation of a good accuracy in this regard could be obtained in the construct validity analysis, however this was not possible due to the lack of an alternative Polish language tool for assessing attitudes towards communication skills.

According to the criterion proposed by Anvik et al, ${ }^{15}$ 3 out of 26 items (1, 12 and 22) were removed from CSAS-P. The fit of the two models was compared using 
Table 6 Comparison of scores obtained in CSAS-P depending on the participation in the training of communication skills and self-assessment communication skills (CS) level

\begin{tabular}{|c|c|c|c|c|c|c|c|}
\hline Subscale/Scale & Factor & $\mathbf{M}$ & SD & $\mathbf{F}$ & P value* & Partial $\eta^{2} \dagger$ & $95 \% \mathrm{Cl}$ \\
\hline \multirow{4}{*}{ PAS-P } & Yes & 46.9 & 8.27 & 23.79 & 0.000 & 0.081 & $0.055 ; 0.104$ \\
\hline & Self-asse & level & & & & & \\
\hline & Low & 43.8 & 8.13 & 14.48 & 0.000 & 0.051 & $0.029 ; 0.070$ \\
\hline & High & 46.3 & 8.08 & & & & \\
\hline \multirow[t]{4}{*}{ NAS-P ${ }^{\dagger}$} & Training & & & & & & \\
\hline & Yes & 44.7 & 8.88 & 44.32 & 0.000 & 0.141 & $0.109 ; 0.169$ \\
\hline & No & 41.5 & 8.27 & & & & \\
\hline & High & 42.7 & 9.21 & & & & \\
\hline \multirow[t]{7}{*}{ CSAS-P } & Training & & & & & & \\
\hline & Yes & 91.6 & 14.3 & 50.71 & 0.000 & 0.158 & $0.125 ; 0.187$ \\
\hline & No & 85.9 & 13.0 & & & & \\
\hline & Self-asse & level & & & & & \\
\hline & Low & 85.4 & 13.33 & 8.65 & 0.000 & 0.031 & $0.014 ; 0.046$ \\
\hline & Average & 86.5 & 12.82 & & & & \\
\hline & High & 88.9 & 14.14 & & & & \\
\hline
\end{tabular}

*Two-way analysis of variance.

†Negatively phrased items were reverse-scored before analysis.

CSAS, Communication Skills Attitude Scale; m, mean; NAS, negative attitude subscale; PAS, positive attitude subscale.

CFA (as done by Busch et al), ${ }^{18}$ and confirmed the reduced form was a better solution than the 26-item scale. Similar reductions in the number of items during validation was done by Ahn et al, ${ }^{19}$ Molinuevo and Torrubia ${ }^{13}$ (6 factors) and Busch et $a l^{18}$ ( 7 factors). Although the Anvik et $a l,{ }^{15}$ Busch et $a l,{ }^{18}$ Laurence et $a l^{24}$ and Molinuevo and Torrubia $^{13}$ (ranging from 2 to 7 items). Finally, CSAS-P consisted of 23 items divided into two subscales: PAS-P (11 items) and NAS-P (12 items).

The differing results of previous individual validation studies regarding the factorial structure may in part be due to language translation. In addition, since the original version of CSAS was designed for medical students, validation of this tool in other groups requires appropriate corrections to the content of certain statements. ${ }^{1824}$ Moreover, while most CSAS studies have imposed a two-factorial structure, ${ }^{11131821-23}$ some studies employed a different subscale structure. ${ }^{151924}$ For example, in the Norwegian CSAS version, three subscales were applied: 'learning', 'importance' and 'respecting,'15; the American version added a fourth subscale-'success' ${ }^{24}$, while the Korean version contained five dimensions-'facilitating interpersonal skills', 'importance within a medical context', 'motivation', 'assessment' and 'overconfidence'. 19 Therefore, when considering the cultural and linguistic differences, as well as the adaptation of CSAS to applications in different target groups, the different factorial models obtained can be accepted as correct.

Internal consistency of PAS-P and NAS-P was good, exceeding the recommended Cronbach's $\alpha$ value of $0.70 .^{32}$ The results correspond to those obtained by Rees $e t$ $a l^{14}$ and Busch et al. ${ }^{18}$ However, the internal consistency of NAS-P was significantly better than that reported by Molinuevo and Torrubia ${ }^{13}$ and Harlak et $a l^{21}$ Results by other authors also generally indicate that the NAS subscale is characterised by worse internal consistency than the PAS subscale.

Test-retest reliability of CSAS-P was slightly better than that obtained during validation of the original CSAS version: there were no cases where the weighted kappa would be $<0.40$, whereas Rees et $a l^{14}$ reported eight such items. However, due to the lack of detailed data from the test-retest analysis carried out by Rees et $a l,{ }^{14}$ it is difficult to assess which items results were worse, and which were better. In addition, better stability was found for the two subscales overall: ICG values were higher in PAS-P and NAS-P (0.895 and 0.789) than in the English version (0.646 and 0.771). Differences in test-retest reliability assessment may result from the number of participants, which was more than two times greater in CSAS-P than 
CSAS (91 vs 39). As it is recommended that a minimum of 100 people should participate in scale stability studies ${ }^{35}$ the results of both validation studies should be cautiously compared. Another weakness of the testretest analysis used in this study is the short time interval between repeated measurements (2 weeks), compared with the recommended period of at least 3 months. ${ }^{35}$ The test-retest analysis also has an error related to the need to repeat the test at a distant time. ${ }^{36}$ The questionnaire presented during the second session was not new to participants, unlike in the first measurement. Two key factors: memory/learning and experience may influence the results of the analysis. If the same tool is used twice, it cannot be ruled out that the attitude or knowledge and skills of a study participant change between the first and the second measurement. Nonetheless, the testretest analysis showed CSAS-P has good absolute stability, indicating that measurements in the PAS-P and NAS-P subscales are resistant to random variability.

There was a fairly high degree of similarity in the attitudes of participants and homogeneity of the measured features, which ensures correct evaluation of the discriminant validity of this tool. The ability of CSAS-P and its subscales to differentiate participants was based on two assumptions. The first concerned the ability of CSAS-P to discriminate differences in the attitudes of people who declared they participated in prior communication skills courses. Indeed, participation in communication skills courses positively influences the attitudes of the respondents, as reflected by the results of this study. This observation is consistent with that of Koponen $e t a l,{ }^{11}$ who found positive attitudes to learning communication skills increased significantly after a pilot course in communication. However, the change of attitudes resulting from participation in communication skills courses is not always obvious, as evidenced by Rees and Sheard ${ }^{25}$ and Harlak et al..$^{22}$ Discrepancies between the results of individual studies may be caused by differences in the way of conducting communication education, its duration and the organisation of the didactic process itself. In this study, participants only declared previous participation in communication courses, which could have different forms and cover a diverse range of content. Therefore, the results on discriminant validity should be treated with caution, and require further confirmation with well-designed studies such as those published by Koponen $e t$ al. ${ }^{11}$

The second assumption tested was the ability to differentiate the results of CSAS-P and its subscales depending on the level of self-assessment of communication skills of the respondents. Self-assessment only had a minor impact on the obtained score, which was similar to the results found by Molinuevo and Torrubia. ${ }^{13}$ It should be emphasised that self-assessment is a highly subjective measure and is influenced by multiple factors, and thus should not be the criterion for determining the discriminant validity of a tool used in psychometry. Indeed, Rees and Sheard ${ }^{25}$ found students rated their skills lower after completing a communication course than before.
The obtained results of psychometric analysis of CSAS-P allow us to assume that it can be used in practice as a tool for evaluating attitude towards learning communication competencies in professionally active nurses. The tool contains two complementary subscales with comparable psychometric properties. Assessment of attitudes can be used for testing newly admitted nurses in order to develop an individual plan of support for improving soft skills, particularly in the field of communication. Moreover, CSAS-P can be used by participants of courses improving professional qualifications either as an element of self-assessment or as an additional tool complementing measurement of learning outcomes.

\section{LIMITATIONS}

The study was conducted during an exam session, and thus, high stress among participants could have influenced the quality of the responses. The study was conducted on nurses who actively chose to improve their professional qualifications, so the group may be unrepresentative of the entire nursing community in Poland. The lack of assessment of criterion-related validity and convergent validity of CSAS-P constituted another limitation of the study.

\section{CONCLUSION}

This validation study confirms CSAS-P is comparable to the original English language version of the scale in terms of reliability and accuracy. The CSAS-P tool can be used both in educational activities, as well as to assess the attitudes of registered nurses working in different positions. However, it should be emphasised that CSAS-P measures attitude towards communication skills. Therefore, the results of CSAS-P should be interpreted with caution. A positive attitude towards communication skills does not always guarantee the need to learn these skills. Further research should look for factors which mediate between a positive attitude towards communication skills and the need to learn these skills.

Acknowledgements The authors would like to thank Halina Zmuda-Trzebiatowska for help and involvement in the organisation of questionnaire surveys at the Center for Postgraduate Education of Nurses and Midwives in Warsaw; Elzbieta Drapiewska for her help in digitising survey data; Charlotte Rees for agreement for the use of CSAS and Charlotte Beer for valuable comments on translation. The authors would like to thank all the nurses and students who participated in the study. Language assistance was provided by Proper Medical Writing Sp. z 0.0., Poland.

Contributors MP and JG contributed to the original conception and design of the survey, and final revision of the manuscript for important intellectual content. LI and $A Z$ designed and contributed to the construction of scale and variables. MJ and $\mathrm{JG}$ contributed to the organisation of the survey and data collection. MP made the psychometric analysis of the data. MP and MJ contributed to interpretation of the data. MP wrote the first draft of the manuscript with revisions by JG.

Funding The authors have not declared a specific grant for this research from any funding agency in the public, commercial or not-for-profit sectors.

Competing interests None declared.

Patient consent for publication Not required. 
Ethics approval The authors sought advice from the Bioethics Committee of Medical University of Warsaw to conduct the presented study. As the 'commission does not issue opinions on the survey, retrospective and other non-invasive scientific studies', approval was not required (AKBE/37/19). Informed consent was obtained verbal from every participant from whom data were collected on completion of the questionnaire. There was no register of persons who had not provided consent to participate in the study. Reasons for refusal were not registered either.

Provenance and peer review Not commissioned; externally peer reviewed.

Open access This is an open access article distributed in accordance with the Creative Commons Attribution Non Commercial (CC BY-NC 4.0) license, which permits others to distribute, remix, adapt, build upon this work non-commercially, and license their derivative works on different terms, provided the original work is properly cited, appropriate credit is given, any changes made indicated, and the use is non-commercial. See: http://creativecommons.org/licenses/by-nc/4.0/.

\section{REFERENCES}

1. Ellison D. Communication skills. Nurs Clin North Am 2015;50:45-57.

2. Foronda C, MacWilliams B, McArthur E. Interprofessional communication in healthcare: An integrative review. Nurse Educ Pract 2016;19:36-40.

3. Manojlovich M. Nurse/physician communication through a sensemaking lens: shifting the paradigm to improve patient safety. Med Care 2010;48:941-6.

4. Schuermeyer IN, Sieke E, Dickstein L, et al. Patients with challenging behaviors: Communication strategies. Cleve Clin J Med 2017;84:535-42.

5. Interprofessional Education Collaborative. Core competencies for interprofessional collaborative practice: 2016 update. Washington, DC: Interprofessional Education Collaborative, 2016.

6. Truglio-Londrigan M, Slyer JT. Shared Decision-Making for Nursing Practice: An Integrative Review. Open Nurs J 2018;12:1-14.

7. Maguire P, Pitceathly C. Key communication skills and how to acquire them. BMJ 2002;325:697-700.

8. Bașoğul C, Özgür G. Role of Emotional Intelligence in Conflict Management Strategies of Nurses. Asian Nurs Res 2016;10:228-33.

9. Hogg MA, Vaughan GM. Social Psychology. 4th ed. London: Prentice-Hall, 2005.

10. Woloschuk W, Harasym PH, Temple W. Attitude change during medical school: a cohort study. Med Educ 2004;38:522-34.

11. Koponen J, Pyörälä E, Isotalus P. Comparing three experiential learning methods and their effect on medical students' attitudes to learning communication skills. Med Teach 2012;34:e198-e207.

12. Myers D, Haslam N, Louis W, et al; Social psychology. Ryde, Australia: McGraw-Hill Education, 2014.

13. Molinuevo B, Torrubia R. Validation of the Catalan version of the communication skills attitude scale (CSAS) in a cohort of south European medical and nursing students. Educ Health 2011;24:499.

14. Rees C, Sheard C, Davies S. The development of a scale to measure medical students' attitudes towards communication skills learning: the Communication Skills Attitude Scale (CSAS). Med Educ 2002;36:141-7.

15. Anvik T, Gude T, Grimstad H, et al. Assessing medical students attitudes towards learning communication skills--which components of attitudes do we measure? BMC Med Educ 2007;7:4.

16. Loureiro E, Severo M, Bettencourt P, et al. Third year medical students perceptions towards learning communication skills: implications for medical education. Patient Educ Couns 2011;85:e265-e271.

17. Loureiro E, Severo M, Ferreira MA. Attitudes of Portuguese medical residents' towards clinical communication skills. Patient Educ Couns 2015;98:1039-43.

18. Busch AK, Rockenbauch K, Schmutzer G, et al. Do medical students like communication? Validation of the German CSAS (Communication Skills Attitude Scale). GMS Z Med Ausbild 2015;32(1):Doc11.

19. Ahn S, Yi YH, Ahn DS. Developing a Korean communication skills attitude scale: comparing attitudes between Korea and the West. Med Educ 2009;43:246-53.

20. Anvik T, Grimstad H, Baerheim A, et al. Medical students' cognitive and affective attitudes towards learning and using communication skills--a nationwide cross-sectional study. Med Teach 2008;30:272-9.

21. Harlak H, Dereboy C, Gemalmaz A. Validation of a Turkish translation of the Communication Skills Attitude Scale with Turkish medical students. Educ Health 2008;21:55.

22. Harlak H, Gemalmaz A, Gurel FS, et al. Communication skills training: effects on attitudes toward communication skills and empathic tendency. Educ Health 2008;21:62.

23. Ihmeideh FM, Al-Omari A, Al-Dababneh K. Attitudes toward Communication Skills among Students'-Teachers' in Jordanian Public Universities. Australian Journal of Teacher Education 2010;35:1-11.

24. Laurence B, Bertera EM, Feimster T, et al. Adaptation of the Communication Skills Attitude Scale (CSAS) to dental students. J Dent Educ 2012;76:1629-38.

25. Rees C, Sheard C. Evaluating first-year medical students' attitudes to learning communication skills before and after a communication skills course. Med Teach 2003;25:302-7.

26. World Health Organization. Research Tools: Process of translation and adaptation of instruments 2017. http://www.who.int/substance abuse/research_tools/translation/en/ (accessed 03.07.2017).

27. Sousa VD, Rojjanasrirat W, Translation RW. Translation, adaptation and validation of instruments or scales for use in cross-cultural health care research: a clear and user-friendly guideline. J Eval Clin Pract 2011;17:268-74.

28. Polit DF, Beck CT. The content validity index: are you sure you know what's being reported? Critique and recommendations. Res Nurs Health 2006:29:489-97.

29. Kaiser HF. The varimax criterion for analytic rotation in factor analysis. Psychometrika 1958;23:187-200.

30. Cattell RB. The Scree Test For The Number Of Factors. Multivariate Behav Res 1966;1:245-76.

31. Schermelleh-Engel K, Moosbrugger $\mathrm{H}$, Müller $\mathrm{H}$. Evaluating the fit of structural equation models: Tests of significance and descriptive goodness-of-fit measures. Methods of psychological research online 2003;8:23-74.

32. Nunnally JC, Bernstein IH. Psychometric theory. 3rd ed. New York: McGraw-Hill, 1967.

33. Sullivan GM. A primer on the validity of assessment instruments. $J$ Grad Med Educ 2011;3:119-20.

34. Lakens D. Calculating and reporting effect sizes to facilitate cumulative science: a practical primer for t-tests and ANOVAs. Front Psychol 2013;4:863.

35. Kline P. Handbook of psychological testing. London: Routledge, 2013.

36. Weir JP. Quantifying test-retest reliability using the intraclass correlation coefficient and the SEM. J Strength Cond Res 2005;19:231-40. 